Resumo

\title{
Características antropométricas associadas ao melhor desempenho esportivo nas atletas de pentatlo militar feminino do Exército
}

Fernando Fracalossi Schramm Bsci, Miriam Raquel Mainenti PhD

Introdução: 0 pentatlo militar é uma das modalidades com maior prestígio no âmbito das forças armadas ao redor do mundo. Dentro deste panorama, com a inserção do público feminino nas forças armadas, cresce a necessidade de estudos que visem aperfeiçoar a seleção e o treinamento das atletas brasileiras. Objetivo: Determinar as características antropométricas das atletas de Pentatlo Militar da equipe do Exército, e identificar quais variáveis estão presentes nas atletas de melhor desempenho na modalidade.

Métodos: Foram coletados os dados de massa corporal total, estatura, comprimentos, circunferências, dobras cutâneas e diâmetros dos membros superiores e inferiores, das cinco atletas que atualmente compõem a equipe de Pentatlo Militar feminino do Exército. Para estimar a densidade corporal e o percentual de gordura foram utilizadas as equações de Salem et al. (2004) e Siri (1961), respectivamente. Também foi analisado o desempenho atlético das atletas nas seletivas para os 60 Jogos Mundiais Militares 2015. A partir dos dados, foram realizadas análises de grupamentos (Cluster), buscando identificar quais características são mais presentes nas atletas que apresentam melhores rendimentos.

Resultados: Foi observada a existência de dois grupos quanto à composição corporal. 0 grupo formado pelas atletas com os maiores valores de massa livre de gordura e circunferência muscular do braço, bem como menores valores de soma de dobras cutâneas e percentual de gordura também compuseram o grupo de melhores atletas quanto a rendimento nas provas. Por outro lado, a análise de cluster das variáveis relacionadas a dimensões corporais não agrupou atletas que também eram similares quanto a desempenho.

Conclusão: 0 presente trabalho concluiu que as melhores atletas apresentavam os melhores valores de composição corporal, mas não de dimensões corporais. Dessa forma, as variáveis de composição corporal devem ser consideradas na seleção de atletas e no acompanhamento do treinamento ao longo da temporada. 